\title{
A Validated HPLC-MS/MS Method for Simultaneous Determination of Militarine and Its Three Metabolites in Rat Plasma: Application to a Pharmacokinetic Study
}

\author{
Hui-Yuan Sun, ${ }^{1,2}$ Lin Zheng, ${ }^{1}$ Zi-Peng Gong $\left(D,{ }^{1}\right.$ Yue-Ting Li, ${ }^{1}$ Chang Yang, ${ }^{1}$ Jie Pan, \\ Yong-Lin Wang, ${ }^{1}$ Ai-Min Wang, ${ }^{3}$ Yong-Jun Li $\mathbb{C}^{3},{ }^{3}$ and Yong Huang $\left(\mathbb{C}^{1}\right.$ \\ ${ }^{1}$ Guizhou Provincial Key Laboratory of Pharmaceutics, State Key Laboratory of Functions and Applications of Medicinal Plants, \\ Guizhou Medical University, Guiyang 550004, China \\ ${ }^{2}$ School of Pharmacy, Guizhou Medical University, Guiyang 550004, China \\ ${ }^{3}$ Guizhou Provincial Engineering Research Center for the Development and Application of Ethnic Medicine and TCM, \\ Guizhou Medical University, Guiyang 550004, China
}

Correspondence should be addressed to Yong-Jun Li; liyongjun026@126.com and Yong Huang; mailofhy@126.com

Hui-Yuan Sun and Lin Zheng contributed equally to this work.

Received 20 December 2018; Accepted 9 April 2019; Published 2 May 2019

Academic Editor: Lucindo Q. Júnior

Copyright (C) 2019 Hui-Yuan Sun et al. This is an open access article distributed under the Creative Commons Attribution License, which permits unrestricted use, distribution, and reproduction in any medium, provided the original work is properly cited.

A rapid, reliable, and sensitive HPLC-electrospray ionization-tandem mass spectrometry (HPLC-MS/MS) method was established and validated for simultaneous determination of militarine and its three metabolites (gastrodin, $\alpha$-isobutylmalic acid, and gymnoside I) in rat plasma. Plasma was acidified with formic acid, and protein was precipitated with methanol. MS/MS with ESI and multiple reaction monitoring at $m / z 725.3 \longrightarrow 457.3,457.1 \longrightarrow 127,304.3 \longrightarrow 107.2,189 \longrightarrow 129$, and $417.1 \longrightarrow 267.1$ was used for determination of militarine, gastrodin, $\alpha$-isobutylmalic acid, gymnoside I, and puerarin (internal standard), respectively. Chromatographic separation was conducted using an ACE UltraCore SuperC18 $(2.1 \times 100 \mathrm{~mm}, 2.5 \mu \mathrm{m})$ column with gradient mobile phase ( $0.1 \%$ formic acid in water and acetonitrile). The lower limits of quantitation for militarine, gastrodin, $\alpha$-isobutylmalic acid, and gymnoside I were $1.02,2.96,1.64$, and $0.3 \mathrm{ng} / \mathrm{mL}$, respectively. The relative standard deviations of intra- and interday measurements were less than $15 \%$, and the method accuracy ranged from $87.4 \%$ to $112.5 \%$. The extraction recovery was $83.52 \%$ $105.34 \%$, and no matrix effect was observed. The three metabolites (gastrodin, $\alpha$-isobutylmalic acid, and gymnoside I) were synchronously detected at $0.83 \mathrm{~h}$, suggesting that militarine was rapidly transformed to gastrodin, $\alpha$-isobutylmalic acid, and gymnoside I. Moreover, the area under the curve (AUC) and $\mathrm{C}_{\max }$ of militarine were significantly lower than those of gastrodin and $\alpha$-isobutylmalic acid, showing that militarine was largely metabolized to gastrodin and $\alpha$-isobutylmalic acid in vivo. The studies on pharmacokinetics of militarine and its three metabolites were of great use for facilitating the clinical application of militarine and were also highly meaningful for the potential development of militarine.

\section{Introduction}

Militarine (Figure 1), a natural glucosyloxybenzyl 2-isobutylmalate containing 2-isobutylmalate as a parent nucleus, is widely distributed in orchids (Orchidaceae) [1], such as Coeloglossum viride (L.) Hartm. var. bracteatum [2] and Bletilla striata (Thunb.) Reichb. f. [3]. Recent pharmacological studies have shown that glucosyloxybenzyl 2-isobutylmalates had antiaging and neuroprotective effects; additionally, they could improve intelligence, learning ability, and memory and prevent senile dementia [4-8]. Militarine is the most abundant active component in B. striata (Thunb.) Reichb. f. [9-12]. B. striata (Thunb.) Reichb. f. has been widely used for the treatment of traumatic bleeding, hemoptysis, and hematemesis owing to its astringent and antihemorrhagic effects. In addition, it has been applied topically to relieve sores, ulcers, chapped skin, and swelling owing to its tissue regenerative capabilities [13-17]. B. striata is a commonly 
<smiles>CC(C)C[C@@](O)(CC(=O)OCc1ccc(O[C@@H]2O[C@H](CO)[C@@H](O)[C@H](O)[C@H]2O)cc1)C(=O)OCc1ccc(O[C@@H]2O[C@H](CO)[C@@H](O)[C@H](O)[C@H]2O)cc1</smiles>

Militarine<smiles>OCc1ccc(O[C@@H]2O[C@H](CO)[C@@H](O)[C@H](O)[C@H]2O)cc1</smiles>

Gastrodin<smiles>CC(C)C[C@@](O)(CC(=O)O)C(=O)OCc1ccc(O[C@H]2OC(CO)[C@@H](O)[C@H](O)[C@H]2O)cc1</smiles>

Gymnoside I

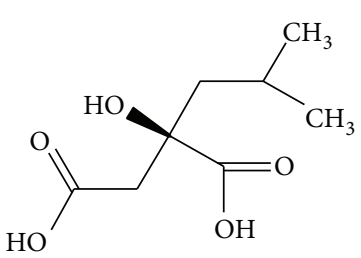

$\alpha$-Isobutylmalic acid<smiles>O=c1c(-c2ccc(O)cc2)coc2c(OC3O[C@H](CO)[C@@H](O)[C@H](O)[C@H]3O)c(O)ccc12</smiles>

Puerarin

FIGURE 1: The chemical structures of gastrodin, $\alpha$-isobutylmalic acid, gymnoside I, militarine, and puerarin (IS).

used traditional Chinese medicine (TCM) [18, 19]. Moreover, the vasodilator and learning and memory-improving effects of militarine have been verified [20,21]. However, only few studies have investigated the potential effects of militarine at present.

To better understand and elucidate the relationship between the pharmacological actions and biotransformation of militarine in vivo, a good knowledge of the ADME processes of this constituent is getting more essential. A rat study on the pharmacokinetics of militarine $(21.51 \mathrm{mg} / \mathrm{kg}$, i.g.) suggested that the plasma concentration $\left(\mathrm{C}_{\max }=30.3 \pm\right.$ $8.61 \mathrm{ng} / \mathrm{mL}, \mathrm{AUC}_{0-\mathrm{t}}=74.3 \pm 37.68 \mathrm{~h} * \mathrm{ng} / \mathrm{mL}$ ) of militarine was low [18]. The militarine was therefore speculated to be intensely metabolized in vivo in this study. However, the metabolism of militarine has not been reported in the literature as far as we know. It has been shown that militarine can be metabolized into gastrodin, $\alpha$-isobutylmalic acid, and gymnoside I in our previous studies. Therefore, to understand the pharmacokinetics of militarine and its metabolites in vivo, a quantitative method was established to determine the dynamic changes of militarine and its metabolites in vivo.

To simultaneously determine militarine and its metabolites in rat plasma, a sensitive bioanalytical method should be employed. In addition, the analytical method should be selective to avoid interference from endogenous substances in the plasma. High-performance liquid chromatographytandem mass spectrometry (HPLC-MS/MS) with multiple reaction monitoring (MRM) mode utilizes two stages of 
TABLE 1: Mass spectra properties of the analytes and IS.

\begin{tabular}{|c|c|c|c|c|c|c|}
\hline Analytes & $\begin{array}{l}\text { Precursor ion } \\
(\mathrm{m} / \mathrm{z})\end{array}$ & $\begin{array}{c}\text { Product ion } \\
(\mathrm{m} / \mathrm{z})\end{array}$ & $\begin{array}{c}\text { Declustering } \\
\text { potential }(\mathrm{DP}, \mathrm{V})\end{array}$ & $\begin{array}{c}\text { Entrance potential } \\
(\mathrm{EP}, \mathrm{V})\end{array}$ & $\begin{array}{c}\text { Collision energy } \\
(\mathrm{CE}, \mathrm{V})\end{array}$ & $\begin{array}{c}\text { Cell exit potential } \\
(\mathrm{CXP}, \mathrm{V})\end{array}$ \\
\hline gastrodin & 304.3 & 107.2 & 57 & 8 & 23 & 18 \\
\hline$\alpha$-isobutylmalic acid & 189.0 & 129.0 & -73 & -10 & -23 & -13 \\
\hline gymnoside I & 457.1 & 127.0 & -77 & -5 & -32 & -6 \\
\hline militarine & 725.3 & 457.3 & -43 & -9 & -22 & -40 \\
\hline puerarin (IS) & 417.1 & 267.1 & 110 & 7 & 35 & 6 \\
\hline
\end{tabular}

mass filtering, which can specifically measure the relative and absolute analyte concentrations [22]. Thus, HPLC-MS/MS could be used for quantitative analysis of drugs and their metabolites.

In this study, a rapid, reliable, and sensitive HPLCMS/MS method was developed and validated for the simultaneous determination of militarine and its three metabolites (gastrodin, $\alpha$-isobutylmalic acid, and gymnoside I) in rat plasma to study the pharmacokinetics of militarine after single oral administration to rats. To the best of our knowledge, this is the first study to determine the pharmacokinetics of militarine and its three metabolites, which could be highly meaningful for the potential development of militarine.

\section{Materials and Methods}

2.1. Reagents and Chemicals. Militarine (purity $\geq 98 \%$ ) was purchased from Chengdu Push Bio-Technology Co., Ltd. (Chengdu, China). Gastrodin (purity: 97.6\%) and puerarin (IS, purity: 95.4\%) were obtained from the National Institutes for Food and Drug Control (Beijing, China). Gymnoside I (purity $\geq 95 \%$ ) and $\alpha$-isobutylmalic acid (purity $\geq 95 \%$ ) were isolated from B. striata (Thunb.) Reichb. f. in our laboratory. The structure and purity of these compounds were confirmed using IR, ${ }^{1} \mathrm{H}$ nuclear magnetic resonance (NMR), MS, and HPLC-UV. Their chemical structures are shown in Figure 1. Methanol, formic acid, and acetonitrile of HPLC-grade were purchased from Merck KGaA Co. (Darmstadt, Germany). Deionized water was obtained using an EPED superpurification system (EPED, Nanjing, China). Other reagents and chemicals were of chromatographic grade.

2.2. Animals. Sprague-Dawley rats $(250 \pm 20 \mathrm{~g})$ were supplied by Changsha Tianqin Biotechnology Co., Ltd. (Changsha, China, certificate No. SCXK (Xiang) 2014-0010). All studies were approved by the Animal Ethics Committee at Guizhou Medical University.

2.3. Instrumentation and Analytical Conditions of HPLCMS/MS. An Acquity HPLC system (Shimadzu Corp., Kyoto, Japan) equipped with a Q-Trap ${ }^{\circledR} 5500$ triple quadruple mass spectrometer (AB Sciex, Foster, CA, USA) was used for HPLC-ESI-MS/MS. Applied Biosystems Analyst software version 1.6.2 was used for data acquisition. The four analytes and the IS (puerarin) were chromatographically separated using an ACE UltraCore SuperC18 $(2.1 \times 100 \mathrm{~mm}, 2.5 \mu \mathrm{m})$ column, and the column temperature was set at $45^{\circ} \mathrm{C}$. The mobile phase was a binary solvent system, consisting of $0.1 \%$ (v/v) formic acid aqueous solution (A) and acetonitrile (B) at a flow rate of $0.2 \mathrm{~mL} / \mathrm{min}$. Gradient elution was used as follows: $10-10 \% \mathrm{~B}$ at $0-1 \mathrm{~min}, 10-30 \% \mathrm{~B}$ at $1-2 \mathrm{~min}, 30-40 \% \mathrm{~B}$ at 2-6 $\mathrm{min}, 40-90 \% \mathrm{~B}$ at 6-6.1 $\mathrm{min}, 90-90 \% \mathrm{~B}$ at 6.1-8.1 $\mathrm{min}, 90-$ $10 \% \mathrm{~B}$ at $8.1-8.2 \mathrm{~min}$, and $10-10 \% \mathrm{~B}$ at $8.2-12 \mathrm{~min}$. The injection volume was $1 \mu \mathrm{L}$.

Detection of the analytes was carried out simultaneously with electrospray negative ionization $\left(\mathrm{ESI}^{-}\right)$and electrospray positive ionization $\left(\mathrm{ESI}^{+}\right)$, and high-purity nitrogen served as both the nebulizing and drying gas. The optimized parameters were as follows: curtain gas (CUR), $0.28 \mathrm{MPa}$; ion source gas 1 (GS1), $0.38 \mathrm{MPa}$; ion source gas 2 (GS2), $0.38 \mathrm{MPa}$; source temperature, $500^{\circ} \mathrm{C}$; and spray voltages, $5500 \mathrm{~V}\left(\mathrm{ESI}^{+}\right)$ and $4500 \mathrm{~V}\left(\mathrm{ESI}^{-}\right)$. The optimized MS parameters are listed in Table 1.

2.4. Preparation of Calibration Standards and QC Sample. The stock solutions of militarine, gastrodin, $\alpha$-isobutylmalic acid, and gymnoside I were separately weighed and dissolved in methanol to obtain final concentrations of 1.8, 1, 2.9, and 1.1 $\mathrm{mg} / \mathrm{mL}$, respectively. Four series of standard mixture working standard solutions were obtained by mixing and diluting the respective stock solutions with methanol. An appropriate amount of puerarin was dissolved in methanol and diluted to obtain the IS solution $(20 \mathrm{ng} / \mathrm{mL})$. The mixture working standard solution $(50 \mu \mathrm{L})$ and IS solution $(20 \mu \mathrm{L})$ were added to blank rat plasma $(100 \mu \mathrm{L})$ to prepare the calibration standard solutions at final concentrations of 1.02-97.92, 2.96$1136.64,1.64-629.76,0.3-57.6$, and $4 \mathrm{ng} / \mathrm{mL}$ for militarine, gastrodin, $\alpha$-isobutylmalic acid, gymnoside I, and the IS, respectively. The QC plasma samples, containing militarine (2.04, 32.64, and $97.92 \mathrm{ng} / \mathrm{mL})$, gastrodin (5.92, 378.88, and $1136.64 \mathrm{ng} / \mathrm{mL}), \alpha$-isobutylmalic acid (3.28, 209.92, and $629.76 \mathrm{ng} / \mathrm{mL})$, and gymnoside I $(0.6,19.2$, and $57.6 \mathrm{ng} / \mathrm{mL})$, were prepared in the same manner.

2.5. Sample Preparation. An aliquot $(100 \mu \mathrm{L})$ of rat plasma, $20 \mu \mathrm{L}$ of IS solution $(20 \mathrm{ng} / \mathrm{mL})$, and $40 \mu \mathrm{L}$ of $1 \%$ formic acid solution were added into a $1.5-\mathrm{mL}$ centrifuge tube and vortexed for $30 \mathrm{~s}$. The mixture was extracted with $400 \mu \mathrm{L}$ of methanol by shaking for 2 min using a vortex mixer. After centrifugation at $13225 \times g$ for $10 \mathrm{~min}$ at $4^{\circ} \mathrm{C}$, the supernatant was quantitatively transferred to a clean centrifuge tube and evaporated to dryness under a stream of nitrogen at $37^{\circ} \mathrm{C}$. The residue was redissolved with $200 \mu \mathrm{L}$ of $50 \%$ methanol and 
TABLE 2: Calibration curves, linear ranges, correlation coefficients, and LLOQ of gastrodin, $\alpha$-isobutylmalic acid, gymnoside I, and militarine in rat plasma $(\mathrm{n}=3)$.

\begin{tabular}{lcccc}
\hline Analytes & Linear regression equation & $\mathrm{R}^{2}$ & Linear range $(\mathrm{ng} / \mathrm{mL})$ & LLOQ $(\mathrm{ng} / \mathrm{mL})$ \\
\hline militarine & $\mathrm{Y}=0.0461 \mathrm{X}-0.0924$ & 0.9997 & $1.02-97.92$ & 1.02 \\
gastrodin & $\mathrm{Y}=0.4226 \mathrm{X}+0.0112$ & 0.9996 & $2.96-1136.64$ & 2.96 \\
$\alpha$-isobutylmalic acid & $\mathrm{Y}=0.2270 \mathrm{X}+0.0174$ & 0.9994 & $1.64-629.76$ & 1.64 \\
gymnoside I & $\mathrm{Y}=0.0436 \mathrm{X}-0.0093$ & 0.9996 & $0.3-57.6$ & 0.3 \\
\hline
\end{tabular}

centrifuged at $13225 \times g$ for $10 \mathrm{~min}$. Then, the supernatant $(1$ $\mu \mathrm{L}$ ) was used for analysis.

2.6. Method Validation. Before using the proposed method to determine militarine, gastrodin, $\alpha$-isobutylmalic acid, and gymnoside I in plasma samples, the method was fully validated for specificity, selectivity, linearity, LLOQ, precision, accuracy, extraction recovery, matrix effect, and stability according to the nonclinical drug pharmacokinetic study technical guideline (China Food And Drug Administration 2014) and the Bioanalytical Method Validation Guideline (Chinese Pharmacopoeia 2015, Vol. 4).

2.6.1. Specificity and Selectivity. Specificity and selectivity were assessed by comparing the chromatograms of blank plasma from six different rats, blank plasma spiked with militarine, gastrodin, $\alpha$-isobutylmalic acid, gymnoside I and the IS, and plasma samples obtained after oral administration of militarine at $60 \mathrm{mg} / \mathrm{kg}$.

2.6.2. Linearity and LLOQ. Calibration curves were constructed, as described in Section 2.4. Linearity was evaluated by plotting the peak area ratio $(y)$ of analytes to IS versus the nominal concentration $(x)$ of analytes by using $1 / \mathrm{x}^{2}$ weighted least squares linear regression. The LLOQ should satisfy the analytical requirement of a signal-to-noise ratio $(\mathrm{S} / \mathrm{N})$ of approximately 10 .

2.6.3. Precision and Accuracy. Precision and accuracy were determined by analyzing the QC samples in five replicates at three concentration levels (namely, low, medium, and high) on the same day (intraday) and on three consecutive validation days (interday).

2.6.4. Extraction Recovery and Matrix Effect. The extraction recovery of the analytes was evaluated by comparing the peak area ratios of pretreated QC samples at low, medium, and high concentrations with those of post-extracted supernatants spiked with the pure reference standards at the same concentrations. The matrix effect was assessed by comparing the peak areas of the analytes in the post-extracted spiked samples with those of the analytes dissolved in methanol at the same concentrations. Analysis of the QC samples was performed in five replicates.

2.6.5. Stability. The stability of analytes was determined using the QC samples at low, medium, and high concentrations $(n=5)$ under various conditions: post-preparation stability $\left(24^{\circ} \mathrm{C}\right.$ in an autosampler for $\left.6 \mathrm{~h}\right)$ and freeze-thaw stability (three times, $-20^{\circ} \mathrm{C}$ to $20^{\circ} \mathrm{C}$ ) on three consecutive days.

2.7. Pharmacokinetic Study. In the pharmacokinetic experiment, the validated method was used to determine the plasma concentrations of militarine and its three metabolites (gastrodin, $\alpha$-isobutylmalic acid, and gymnoside I) in six healthy SD rats weighing $250 \pm 20 \mathrm{~g}$. Rats were fasted with free access to water for $12 \mathrm{~h}$ before the experiment. They received a single oral dose $(60 \mathrm{mg} / \mathrm{kg})$ of militarine. Blood samples of $300 \mu \mathrm{L}$ were collected from the external right jugular vein into heparinized tubes at the designated time points $(0$, $0.033,0.083,0.167,0.33,0.5,1,1.5,2,4,6,8,12,24$, and 36 h). The heparinized blood samples were centrifuged at 3306 $\times g$ for $10 \mathrm{~min}$ at $4^{\circ} \mathrm{C}$, and the supernatant was transferred into clean centrifuge tubes and stored at $-20^{\circ} \mathrm{C}$ until analysis.

2.8. Pharmacokinetic Data Analysis. The pharmacokinetic parameters of the four analytes were calculated by Phoenix WinNonlin version 6.4 software (Pharsight Corporation, Mountain View, USA) using noncompartmental analysis. These parameters included the AUC from $0 \mathrm{~h}$ to the time of last measurable concentration $\left(\mathrm{AUC}_{0-\mathrm{t}}\right)$, AUC from 0 to infinity $\left(\mathrm{AUC}_{0-\infty}\right), \mathrm{MRT}_{0-\mathrm{t}}, \mathrm{MRT}$ to infinity $\left(\mathrm{MRT}_{0-\infty}\right)$, $\mathrm{C}_{\text {max }}$, and time to $\mathrm{C}_{\max }\left(\mathrm{T}_{\max }\right)$. All results were expressed as the means \pm standard deviations (SD).

\section{Results and Discussion}

\subsection{Method Validation}

3.1.1. Specificity and Selectivity. The chromatograms of blank rat plasma, blank rat plasma spiked with standard solutions and IS, and rat plasma after oral militarine administration are shown in Figure 2. The retention times of gastrodin, $\alpha$ isobutylmalic acid, gymnoside I, militarine, and the IS (puerarin) were $1.52,4.96,5.4,5.65$, and $4.45 \mathrm{~min}$, respectively. No significant interference from endogenous substances with the analytes and IS was observed, compared to the chromatogram of blank rat plasma sample.

3.1.2. Linearity and Lower Limit of Quantitation (LLOQ). Table 2 shows the typical calibration curves, linearity ranges, coefficients of correlation, and LLOQ for militarine, gymnoside I, gastrodin, and $\alpha$-isobutylmalic acid. All the four analytes exhibited good linearity with correlation coefficients within the range of 0.9994-0.9997. 


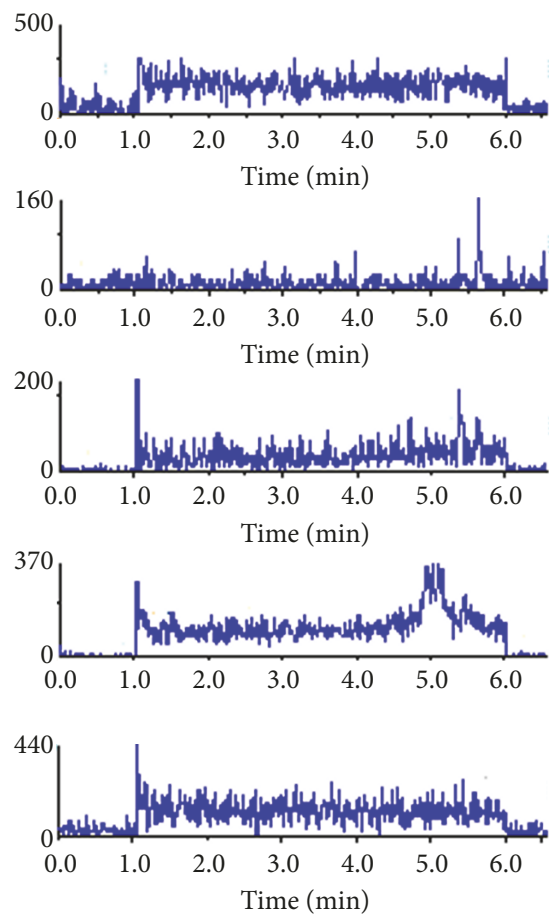

(a)
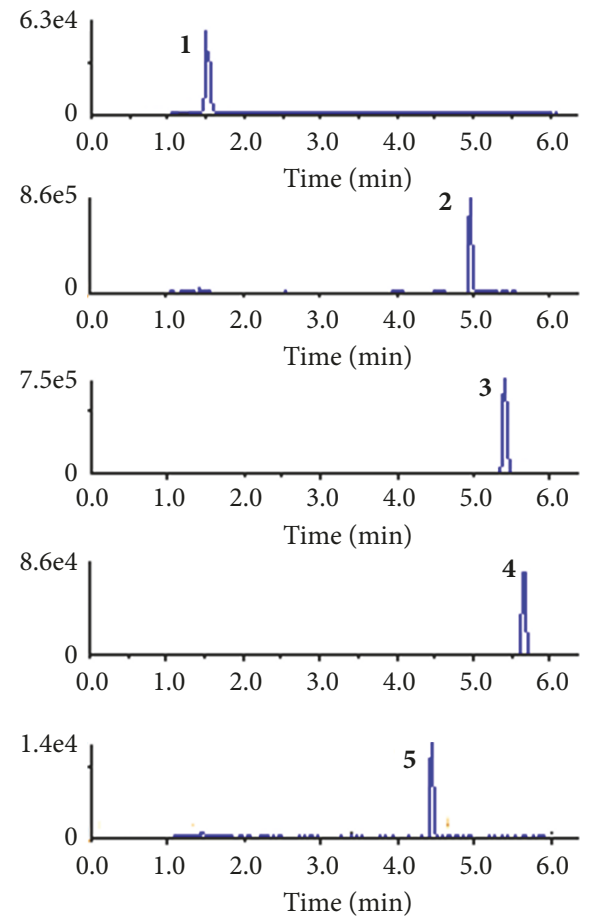

(b)
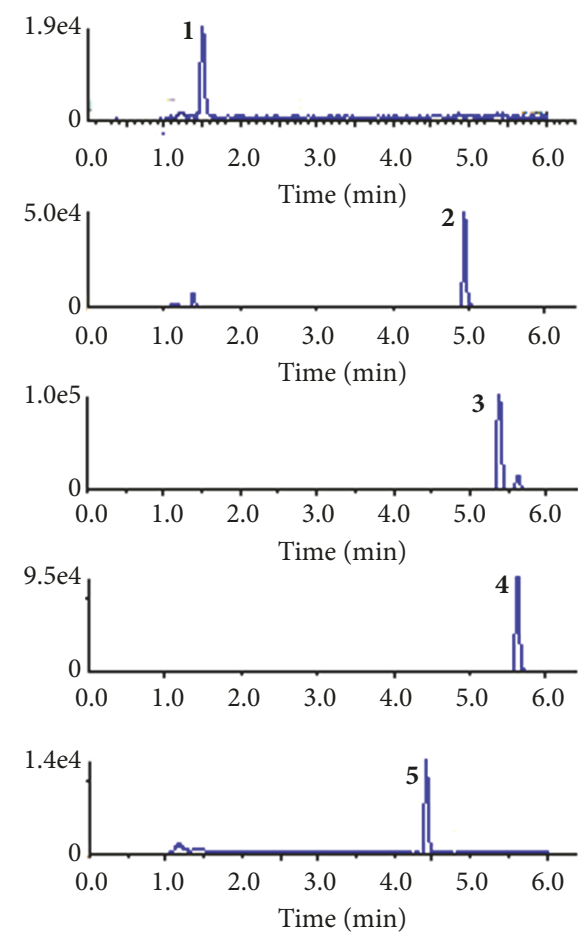

(c)

FIGURE 2: The chromatograms of the analytes and puerarin (IS) in rat plasma. (a) A blank rat plasma sample; (b) a blank rat plasma sample spiked with gastrodin $(378.88 \mathrm{ng} / \mathrm{mL}), \alpha$-isobutylmalic acid $(209.92 \mathrm{ng} / \mathrm{mL})$, gymnoside I $(19.2 \mathrm{ng} / \mathrm{mL})$, militarine $(32.64 \mathrm{ng} / \mathrm{mL})$ and IS (4 $\mathrm{ng} / \mathrm{mL}$ ); (c) a plasma sample at $30 \mathrm{~min}$ after oral administration militarine to rats. (1) Gastrodin, (2) $\alpha$-isobutylmalic acid, (3) gymnoside I, (4) militarine, and (5) puerarin (IS).

TABLE 3: Summary of precision and accuracy of the four analytes in rat plasma $(n=5)$.

\begin{tabular}{|c|c|c|c|c|c|c|c|}
\hline \multirow[b]{2}{*}{ Analytes } & \multirow{2}{*}{$\begin{array}{c}\text { Spiked } \\
\text { Concentration } \\
(\mathrm{ng} / \mathrm{mL})\end{array}$} & \multicolumn{3}{|c|}{ Intra-day } & \multicolumn{3}{|c|}{ Inter-day } \\
\hline & & $\begin{array}{c}\text { Calculated } \\
\text { concentration } \\
(\mathrm{ng} / \mathrm{mL})\end{array}$ & $\begin{array}{l}\text { Precision } \\
(\mathrm{RSD}, \%)\end{array}$ & $\begin{array}{c}\text { Accuracy } \\
(\%)\end{array}$ & $\begin{array}{c}\text { Calculated } \\
\text { concentration } \\
(\mathrm{ng} / \mathrm{mL})\end{array}$ & $\begin{array}{l}\text { Precision } \\
(\mathrm{RSD}, \%)\end{array}$ & $\begin{array}{c}\text { Accuracy } \\
(\%)\end{array}$ \\
\hline \multirow{3}{*}{ militarine } & 2.04 & $2.22 \pm 0.15$ & 6.9 & 108.9 & $1.87 \pm 0.21$ & 11.4 & 91.5 \\
\hline & 32.64 & $31.56 \pm 2.37$ & 7.5 & 96.7 & $36.73 \pm 1.87$ & 5.1 & 112.5 \\
\hline & 97.92 & $105.10 \pm 4.67$ & 4.4 & 107.3 & $87.36 \pm 5.97$ & 6.8 & 89.2 \\
\hline \multirow{3}{*}{ gastrodin } & 5.92 & $6.48 \pm 0.69$ & 10.6 & 109.5 & $6.51 \pm 0.63$ & 9.7 & 109.9 \\
\hline & 378.88 & $341.90 \pm 18.12$ & 5.3 & 90.2 & $335.42 \pm 25.02$ & 7.5 & 88.5 \\
\hline & 1136.64 & $1253.71 \pm 44.13$ & 3.5 & 110.3 & $1051.16 \pm 128.45$ & 12.2 & 92.5 \\
\hline \multirow{3}{*}{$\alpha$-isobutylmalic acid } & 3.28 & $3.05 \pm 0.38$ & 12.5 & 93.0 & $3.59 \pm 0.37$ & 10.3 & 109.4 \\
\hline & 209.92 & $230.72 \pm 13.11$ & 5.7 & 109.9 & $217.31 \pm 27.23$ & 12.5 & 103.5 \\
\hline & 629.76 & $672.08 \pm 49.73$ & 7.4 & 106.7 & $575.98 \pm 51.20$ & 8.9 & 91.5 \\
\hline \multirow{3}{*}{ gymnoside I } & 0.6 & $0.58 \pm 0.05$ & 8.3 & 96.6 & $0.52 \pm 0.05$ & 10.1 & 87.4 \\
\hline & 19.2 & $16.99 \pm 1.97$ & 11.6 & 88.5 & $17.53 \pm 2.32$ & 13.2 & 91.3 \\
\hline & 57.6 & $52.70 \pm 2.82$ & 5.4 & 91.5 & $61.33 \pm 5.70$ & 9.3 & 106.5 \\
\hline
\end{tabular}

3.1.3. Precision and Accuracy. The intra- and interday precision and accuracy were evaluated in five replicate analyses of quality control (QC) samples at three concentrations. Results are summarized in Table 3. The relative standard deviations of intra- and interday measurements were less than $15 \%$, and the RSD (\%) values of accuracy of three analytes were within the range of $87.4-112.5 \%$. These results showed that the method was acceptable.

3.1.4. Extraction Recovery and Matrix Effect. The mean extraction recovery and matrix effect of the four analytes are shown in Table 4. The extraction recoveries of the four 
TABLE 4: Summary of recovery and matrix effect of the four analytes in rat plasma $(n=5)$.

\begin{tabular}{|c|c|c|c|c|c|}
\hline \multirow{2}{*}{ Analytes } & \multirow{2}{*}{ Spiked Concentration $(\mathrm{ng} / \mathrm{mL})$} & \multicolumn{2}{|c|}{ Extraction Recovery } & \multicolumn{2}{|c|}{ Matrix effect } \\
\hline & & Mean \pm SD (\%) & RSD (\%) & Mean \pm SD (\%) & RSD (\%) \\
\hline \multirow{3}{*}{ militarine } & 2.04 & $105.34 \pm 7.91$ & 7.5 & $102.82 \pm 8.53$ & 8.3 \\
\hline & 32.64 & $92.40 \pm 10.65$ & 11.5 & $87.61 \pm 11.49$ & 13.1 \\
\hline & 97.92 & $89.92 \pm 8.99$ & 10.0 & $92.52 \pm 4.75$ & 5.1 \\
\hline \multirow{3}{*}{ gastrodin } & 5.92 & $85.71 \pm 6.01$ & 7.0 & $88.80 \pm 9.22$ & 10.4 \\
\hline & 378.88 & $92.49 \pm 5.40$ & 5.8 & $85.43 \pm 4.63$ & 5.4 \\
\hline & 1136.64 & $87.58 \pm 8.20$ & 9.4 & $92.76 \pm 6.78$ & 7.3 \\
\hline \multirow{3}{*}{$\alpha$-isobutylmalic acid } & 3.28 & $93.14 \pm 3.56$ & 3.8 & $93.48 \pm 8.07$ & 8.6 \\
\hline & 209.92 & $89.10 \pm 10.88$ & 12.2 & $84.42 \pm 10.91$ & 12.9 \\
\hline & 629.76 & $95.71 \pm 10.17$ & 10.6 & $89.30 \pm 10.13$ & 11.3 \\
\hline \multirow{3}{*}{ gymnoside I } & 0.6 & $93.02 \pm 3.53$ & 3.8 & $85.41 \pm 3.42$ & 4.0 \\
\hline & 19.2 & $90.40 \pm 12.08$ & 13.4 & $90.14 \pm 8.92$ & 9.9 \\
\hline & 57.6 & $83.52 \pm 2.86$ & 3.4 & $88.30 \pm 10.78$ & 12.2 \\
\hline
\end{tabular}

TABLE 5: Stability of the four analytes in rat plasma under various storage conditions $(n=5)$.

\begin{tabular}{|c|c|c|c|c|c|c|c|}
\hline \multirow[b]{2}{*}{ Analytes } & \multirow[b]{2}{*}{$\begin{array}{c}\text { Spiked } \\
\text { Concentration } \\
(\mathrm{ng} / \mathrm{mL})\end{array}$} & \multicolumn{3}{|c|}{ Post-preparation stability } & \multicolumn{3}{|c|}{ Freeze-thaw stability } \\
\hline & & $\begin{array}{l}\text { Calculated } \\
\text { concentration } \\
(\mathrm{ng} / \mathrm{mL})\end{array}$ & $\begin{array}{l}\text { Precision } \\
(\mathrm{RSD}, \%)\end{array}$ & $\begin{array}{c}\text { Accuracy } \\
(\%)\end{array}$ & $\begin{array}{c}\text { Calculated } \\
\text { concentration } \\
(\mathrm{ng} / \mathrm{mL})\end{array}$ & $\begin{array}{l}\text { Precision } \\
(\mathrm{RSD}, \%)\end{array}$ & $\begin{array}{c}\text { Accuracy } \\
(\%)\end{array}$ \\
\hline \multirow{3}{*}{ militarine } & 2.04 & $1.85 \pm 0.14$ & 7.3 & 90.6 & $2.09 \pm 0.21$ & 9.9 & 102.6 \\
\hline & 32.64 & $33.47 \pm 2.22$ & 6.6 & 102.5 & $35.09 \pm 1.41$ & 4.0 & 107.5 \\
\hline & 97.92 & $96.57 \pm 5.42$ & 5.6 & 98.6 & $95.68 \pm 7.57$ & 7.9 & 97.7 \\
\hline \multirow{3}{*}{ gastrodin } & 5.92 & $6.29 \pm 0.60$ & 9.6 & 106.2 & $6.11 \pm 0.59$ & 9.6 & 103.2 \\
\hline & 378.88 & $357.97 \pm 11.85$ & 3.3 & 94.5 & $410.63 \pm 26.77$ & 6.5 & 108.4 \\
\hline & 1136.64 & $1080.94 \pm 52.32$ & 4.8 & 95.1 & $1087.88 \pm 31.11$ & 2.9 & 95.7 \\
\hline \multirow{3}{*}{$\alpha$-isobutylmalic acid } & 3.28 & $3.03 \pm 0.15$ & 4.9 & 92.4 & $3.21 \pm 0.27$ & 8.5 & 97.9 \\
\hline & 209.92 & $213.51 \pm 6.62$ & 3.1 & 101.7 & $213.32 \pm 13.89$ & 6.5 & 101.6 \\
\hline & 629.76 & $647.02 \pm 27.63$ & 4.3 & 102.7 & $607.66 \pm 32.21$ & 5.3 & 96.5 \\
\hline \multirow{3}{*}{ gymnoside I } & 0.60 & $0.62 \pm 0.05$ & 8.6 & 103.6 & $0.63 \pm 0.05$ & 8.5 & 104.6 \\
\hline & 19.2 & $18.65 \pm 1.34$ & 7.2 & 97.1 & $20.14 \pm 1.49$ & 7.4 & 104.9 \\
\hline & 57.6 & $54.29 \pm 3.67$ & 6.8 & 94.3 & $54.50 \pm 1.91$ & 3.5 & 94.6 \\
\hline
\end{tabular}

analytes were within the range of $83.52-105.34 \%$, showing that the recovery of analytes was consistent and reproducible. The matrix effects ranged from $84.42 \%$ to $102.82 \%$. The results indicated that no endogenous substances significantly influenced the quantification of all the analytes.

3.1.5. Stability. Table 5 shows the stability data of the four analytes. Results showed that the relative standard deviations (RSD) of post-preparation stability $\left(24^{\circ} \mathrm{C}\right.$ in an autosampler for $6 \mathrm{~h}$ ) and freeze-thaw stability (three times, -20 to $20^{\circ} \mathrm{C}$ ) on consecutive three days of all analytes were $\leq 9.6 \%$ and $\leq 9.9 \%$, respectively. These results indicated that the four analytes were stable and applicable within the acceptable limit.

3.2. Pharmacokinetics. The validated HPLC-MS/MS method was successfully applied for simultaneous determination of militarine and its three metabolites after single oral administration of militarine at $60 \mathrm{mg} / \mathrm{kg}$ to six healthy rats.
The primary pharmacokinetic parameters calculated using noncompartmental analysis are summarized in Table 6. The mean plasma concentration-time curves of militarine and its three metabolites are shown in Figure 3.

Two minutes after administration, militarine could be detected in plasma, indicating that it was rapidly absorbed. Militarine reached the peak plasma concentration $\left(\mathrm{C}_{\max }=\right.$ $62.31 \pm 10.01 \mathrm{ng} / \mathrm{mL}$ ) at approximately $0.21 \mathrm{~h}$ and was rapidly eliminated with a mean retention time to the last sampling time $\left(\mathrm{MRT}_{0-\mathrm{t}}\right)$ of $3.29 \pm 0.36 \mathrm{~h}$. The three metabolites (gastrodin, $\alpha$-isobutylmalic acid, and gymnoside I) were synchronously detected at $0.83 \mathrm{~h}$, suggesting that militarine was rapidly transformed to gastrodin, $\alpha$-isobutylmalic acid, and gymnoside I. Moreover, the area under the curve (AUC) and $\mathrm{C}_{\max }$ of militarine were significantly lower than those of gastrodin and $\alpha$-isobutylmalic acid, showing that militarine was largely metabolized to gastrodin and $\alpha$-isobutylmalic acid in vivo. The $\mathrm{AUC}$ and $\mathrm{C}_{\max }$ of gymnoside $\mathrm{I}$ were comparable to that of militarine. These results suggested 
TABLE 6: The pharmacokinetic parameters of militarine and its three metabolites after the single oral dose $(60 \mathrm{mg} / \mathrm{kg})$ of militarine to rats ( $\mathrm{n}$ $=6$, mean $\pm \mathrm{SD})$.

\begin{tabular}{lccccc}
\hline \multirow{2}{*}{ Parameters } & Unit & \multicolumn{3}{c}{ Analytes } \\
& & militarine & gastrodin & $\alpha$-isobutylmalic acid & gymnoside I \\
\hline $\mathrm{T}_{\max }$ & $\mathrm{h}$ & $0.21 \pm 0.08$ & $1.38 \pm 0.25$ & $7.50 \pm 1.00$ & $1.88 \pm 0.25$ \\
$\mathrm{C}_{\max }$ & $\mathrm{ng} / \mathrm{mL}$ & $62.31 \pm 10.01$ & $620.50 \pm 75.98$ & $466.86 \pm 96.49$ & $32.82 \pm 5.92$ \\
$\mathrm{AUC}_{0-\mathrm{t}}$ & $\mathrm{h} * \mathrm{ng} / \mathrm{mL}$ & $123.41 \pm 9.95$ & $2077.40 \pm 358.66$ & $6285.32 \pm 1319.90$ & $122.27 \pm 9.54$ \\
$\mathrm{AUC}_{0-\infty}$ & $\mathrm{h} * \mathrm{ng} / \mathrm{mL}$ & $140.34 \pm 10.02$ & $2116.92 \pm 384.37$ & $6316.32 \pm 1327.54$ & $123.73 \pm 9.81$ \\
$\mathrm{MRT}_{0-\mathrm{t}}$ & $\mathrm{h}$ & $3.29 \pm 0.36$ & $2.66 \pm 0.50$ & $8.71 \pm 0.67$ & $3.28 \pm 0.39$ \\
$\mathrm{MRT}_{0-\infty}$ & $\mathrm{h}$ & $5.03 \pm 0.88$ & $2.88 \pm 0.63$ & $8.87 \pm 0.68$ & $3.41 \pm 0.39$ \\
\hline
\end{tabular}
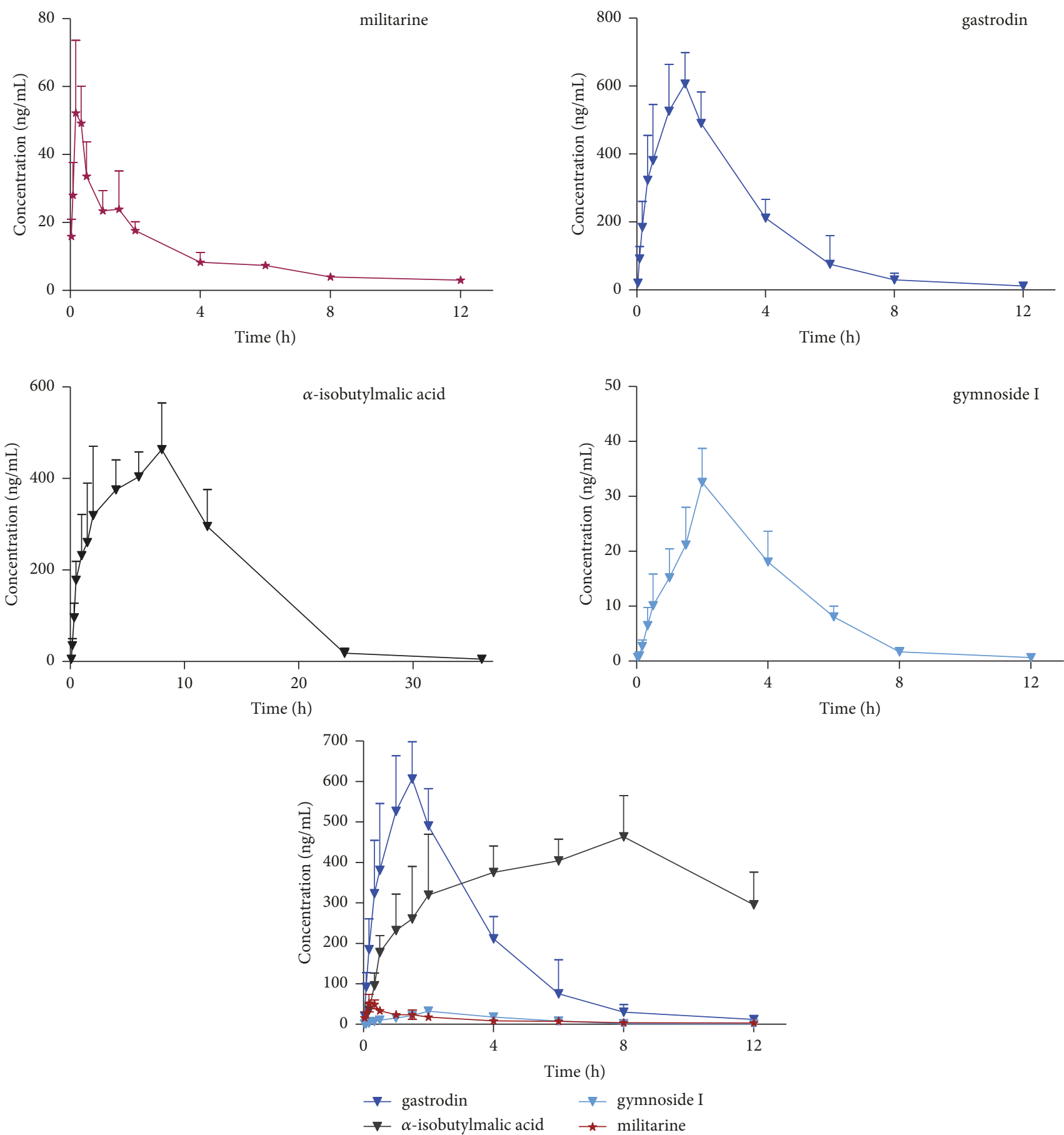

FIgURE 3: Mean plasma concentration-time curves of militarine and its three metabolites after the single oral dose (60 mg/kg) of militarine to rats $(n=6)$. 
that the cleavage of ester bonds in militarine could produce gymnoside I and gastrodin, and then the cleavage of the ester bonds in gymnoside I could produce gastrodin and $\alpha$-isobutylmalic acid, which could account for the high AUC and $\mathrm{C}_{\max }$ values of gastrodin and $\alpha$-isobutylmalic acid, compared to those of militarine and gymnoside I. The order of AUC values was $\alpha$-isobutylmalic > gastrodin > militarine > gymnoside I, suggesting that militarine could be adequately transformed to the three metabolites in vivo, and the most abundant constituents in the blood were $\alpha$-isobutylmalic acid and gastrodin.

A drug candidate should have a favorable pharmacokinetic behavior to allow new drug development [23]. Militarine was shown to improve white matter lesions (WMLs) and cognitive impairment in rat chronic hypoperfusion model; additionally, it showed a dose-dependent and endothelium-dependent relaxing effect in rat isolated thoracic aorta rings [20,21]. However, our results showed that the blood concentration of militarine was very low after oral administration, and gastrodin and $\alpha$-isobutylmalic acid were the main components detected in the plasma after single oral administration $(60 \mathrm{mg} / \mathrm{kg})$ of militarine to rats. Gastrodin, the main bioactive ingredient in the widely known Chinese medicine "Tianma" (Rhizoma Gastrodia), has been widely used in China to treat central nervous system (CNS) diseases, such as neuralgia, vertigo, neurasthenia, epilepsy, insomnia, and headache [24-28]. Additionally, it has been shown to improve learning and memory and to exhibit vasodilator effects $[29,30] . \alpha$-Isobutylmalic acid exhibited longer MRT and higher $\mathrm{C}_{\max }$ than those of militarine, indicating that $\alpha$ isobutylmalic acid might exert therapeutic effects in vivo. In addition, glucosyloxybenzyl 2-isobutylmalates, such as gymnoside I, could improve intelligence and prevent senile dementia $[1,31]$. Therefore, further studies are required to verify these effects of gymnoside I. The in vivo effectiveness of bioactive constituents depends to a great extent on their blood concentration, as well as the activity of their metabolites. Thus, the effects of militarine in vivo might be, in part, attributed to the activity of its metabolites. We believe that the results of this pharmacokinetic study of militarine after its oral administration in rats could provide the basis for the development of militarine and its clinical applications.

\section{Conclusions}

In this study, a sensitive, rapid, and convenient HPLCMS/MS method to determine militarine and its three metabolites (gastrodin, $\alpha$-isobutylmalic acid, and gymnoside I) in rat plasma was successfully established and validated. The validated method was successfully used in a preclinical pharmacokinetic study in rats after oral administration of militarine. This study determined the pharmacokinetic behavior of militarine and its metabolites. The current pharmacokinetic study of militarine not only provided significant and valuable clinical guidance toward the application of this constituent but also could predict the druggability of bioactive metabolites, which is essential in drug development.

\section{Data Availability}

The data used to support the findings of this study are included within the article.

\section{Conflicts of Interest}

The authors declare that there are no conflicts of interest regarding the publication of this paper.

\section{Acknowledgments}

This research was supported by the National Natural Science Foundation of China (No. U1812403/81860323/81460630); Guizhou Science and Technology Department (No. [2017] 5601, [2016]5613/5677); Guiyang Science and Technology Bureau (No. [2017]30-29); and Guizhou Education Department (No. KY[2018]050).

\section{References}

[1] M. Li, Studies on The Chemical Constituents and Quantitative Determination of Glucosyloxybenzyl 2-Isobutylmalates in The Tubers of Gymnadenia Conopsea, eking Union Medical College, Beijing, China, 2007.

[2] S.-Y. Huang, J.-G. Shi, Y.-C. Yang, and S.-L. Hu, "Studies on the chemical constituents of Coeloglossum viride (L.) Hartm. var. bracteatum (Willd.) Richter," Acta Pharmaceutica Sinica, vol. 37, no. 3, pp. 199-203, 2002.

[3] G. X. Han, L. X. Wang, W. D. Zhang, M. L. Wang, H. T. Liu, and J. H. Xiao, "Studies on chemical constituents of Bletilla striata II," Academic Journal of Second Military Medical University, vol. 23, no. 9, pp. 1029-1031, 2002.

[4] J. Wang, C. Y. Yu, and J. J. Zhang, "Improvement of Coeloglossum viride var. bracteatum extract in IBO-induced AD rats," Journal of Basic and Clinical Medicine, vol. 30, no. 8, pp. 831$835,2010$.

[5] C.-Y. Yu and J.-J. Zhang, "Effect of the extract from Coeloglossum viride (L.) Hartm. Var. bracteatum (Willd.) Richter on learning and memory in dementia rats," Chinese Journal of New Drugs, vol. 18, no. 1, pp. 63-66, 2009.

[6] D. Zhang and J.-J. Zhang, "Effect of Coeloglossum. viride var. bracteatum extract on oxidation injury in sub-acute senescent model mice," Acta Academiae Medicinae Sinicae, vol. 27, no. 6, pp. 729-733, 2005.

[7] D. Zhang and J.-J. Zhang, "Effects of Coeloglossum viride (L.) Hartm. var. bracteatum (Willd.) Richter extract on memory and apoptosis-related protein expression of subacute aging mice," Chinese Journal of Pharmacology and Toxicology, vol. 19, no. 4, pp. 259-262, 2005.

[8] D. Zhang, G. Liu, J. Shi, and J. Zhang, "Coeloglossum viride var. bracteatum extract attenuates $\mathrm{D}$-galactose and $\mathrm{NaNO}_{2}$ induced memory impairment in mice," Journal of Ethnopharmacology, vol. 104, no. 1-2, pp. 250-256, 2006.

[9] L. Chen, C. X. Liu, X. L. He, and X. H. Zhang, "Simultaneous determination of militarine, protocatechuic acid and caffeic acid in bletilla striata by LC-MS/MS," China Pharmacist, vol. 18, no. 2, pp. 230-232, 2013.

[10] A.-M. Wang, Y. Yan, B. Lan, S.-G. Liao, Y.-L. Wang, and Y.J. Li, "Simultaneous determination of nine chemical markers 
of Bletillae Rhizoma by ultra performance liquid chromatography," China Journal of Chinese Materia Medica, vol. 39, no. 11, pp. 2051-2055, 2014.

[11] L. Y. Huang, S. S. Mao, and L. Chen, "Determination of Militarine in Bletilla striata from the Different Habitat by HPLC," Research and Practice of Chinese Medicines, vol. 27, no. 5, pp. 16-19, 2013.

[12] X. He, A. M. Wang, Y. J. Li, Y. L. Wang, and S. Y. Zhou, "Determination of militarine Rhizom a Bletillae by HPLC," China Journal of Chinese Materia Medica, vol. 34, no. 16, pp. 2076-2078, 2009.

[13] F. F. Zhao, N. C. Lin, X. Yang et al., "Effects of a nonpolysaccharide fraction of Bletilla striata on platelet activation and hemorheology in rats," Chinese Traditional Patent Medicine, vol. 39, no. 2, pp. 244-249, 2017.

[14] F.-F. Zhao, X. Yang, D. Xu et al., "Hemostatic effect and mechanism of a non-polysaccharide fraction of bletilla striata," Chinese Pharmacological Bulletin, vol. 32, no. 8, pp. 1121-1126, 2016.

[15] A. J. Sun, S. Q. Pang, and G. Q. Wang, "Advances of chemical constituents and pharmacological activities of Bletilla striata," Global Traditional Chinese Medicine, vol. 9, no. 4, pp. 507-511, 2016.

[16] L. F. Zhang, J. H. Hu, and Y. Q. Zhang, "Rsearch progress on pharmacological action of Bletilla rhizoma," Modern Chinese Medicine, vol. 16, no. 1, pp. 83-86, 2014.

[17] X. He, X. Wang, J. Fang et al., "Bletilla striata: medicinal uses, phytochemistry and pharmacological activities," Journal of Ethnopharmacology, vol. 195, pp. 20-38, 2017.

[18] Y. Wang, B. Zhang, J. Zhang et al., "Qualitative and quantitative analysis of Yifei Tongluo granules to identify main bioactive components using LC-DAD/MS and pharmacokinetic studies," Journal of Pharmaceutical and Biomedical Analysis, vol. 163, pp. 130-136, 2019.

[19] L. Huang, H. L. Chen, and L. L. Li, "Determination of militarine in Weikangling capsules by HPLC," Drug Standards of China, vol. 19, no. 4, pp. 261-264, 2018.

[20] Y. Wang, X. Y. Zhang, X. Y. Li, S. Li, and J. J. Zhang, "Militarine alleviates white matter damage and cognitive impairment in rats with chronic cerebral hypoperfusion," Acta Pharmaceutica Sinica, vol. 51, no. 5, pp. 738-742, 2016.

[21] X. X. Xu, G. T. Xu, X. P. Li, X. Zhong, H. W. Jian, and Z. $\mathrm{Xu}$, "Effect and mechanism of militarine in relaxing isolated thoracic aorta rings in rats," Chinese Archives of Traditional Chinese Medicine, vol. 33, no. 3, pp. 617-620, 2015.

[22] K. Xiong, T. Gao, T. Zhang, Z. Wang, and H. Han, "Simultaneous determination of gentiopicroside and its two active metabolites in rat plasma by LC-MS/MS and its application in pharmacokinetic studies," Journal of Chromatography B, vol. 1065-1066, pp. 1-7, 2017.

[23] X. Zhang, S. Liu, Z. Pi, Z. Liu, and F. Song, "Simultaneous quantification method for comparative pharmacokinetics studies of two major metabolites from geniposide and genipin by online mircrodialysis-UPLC-MS/MS," Journal of Chromatography B, vol. 1041-1042, pp. 11-18, 2017.

[24] Z. Zhang, P. Ma, Y. Xu et al., "Preventive effect of gastrodin on cognitive decline after cardiac surgery with cardiopulmonary bypass: a double-blind, randomized controlled study," Journal of Huazhong University of Science and Technology (Medical Science), vol. 31, no. 1, pp. 120-127, 2011.
[25] J. Xu and S. Guo, "Retrospect on the research of the cultivation of Gastrodia elata $\mathrm{Bl}$, a rare traditional Chinese medicine," Chinese Medical Journal, vol. 113, no. 8, pp. 686-692, 2000.

[26] R. Zhang, Z. Peng, H. Weng et al., "Gastrodin ameliorates depressive-like behaviors and up-regulates the expression of BDNF in the hippocampus and hippocampal-derived astrocyte of rats," Neurochemical Research, vol. 39, no. 1, pp. 172-179, 2014.

[27] Y. Jia, X. Li, H. Xie et al., "Analysis and pharmacokinetics studies of gastrodin and p-hydroxybenzyl alcohol in dogs using ultra fast liquid chromatography-tandem mass spectrometry method," Journal of Pharmaceutical and Biomedical Analysis, vol. 99, no. 10, pp. 83-88, 2014.

[28] M.-T. Hsieh, C.-R. Wu, and C.-F. Chen, "Gastrodin and phydroxybenzyl alcohol facilitate memory consolidation and retrieval, but not acquisition, on the passive avoidance task in rats," Journal of Ethnopharmacology, vol. 56, no. 1, pp. 45-54, 1997.

[29] Z. H. Liu, H. Ma, W. P. Wang et al., "Structure-activity relationship of gastrodin and parishins on learning and memory deficits induced by scopolamine," Acta Pharmaceutica Sinica, vol. 51, no. 5, pp. 743-748, 2016.

[30] Y. Zhang, T. Yu, J. Xu, X. Bian, J. Xu, and Y. Liu, "Effect and mechanism of gastrodin in relaxing isolated thoracic aorta rings in rats," China Journal of Chinese Materia Medica, vol. 37, no. 14, pp. 2135-2138, 2012.

[31] J. Liu, Study on The Mass Spectrometric Analytical Method of an Active Fraction from Gymnadenia Conopsea $R$. BR. and Its Metabolism, Peking and Union Medical College, Beijing, China, 2010 . 


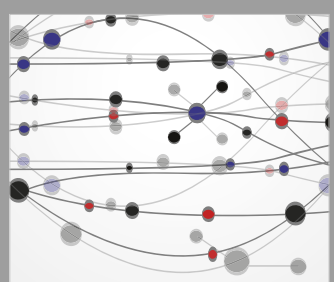

The Scientific World Journal
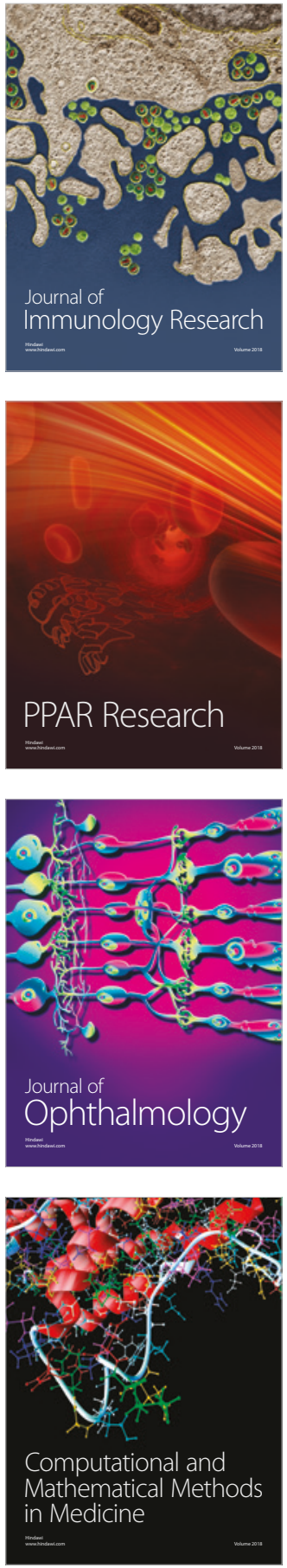

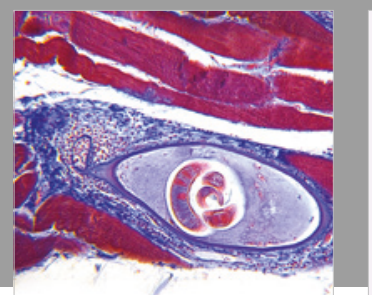

Gastroenterology Research and Practice

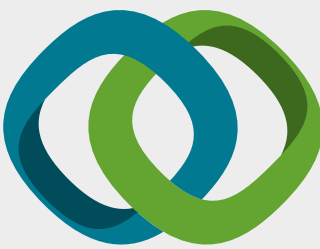

\section{Hindawi}

Submit your manuscripts at

www.hindawi.com
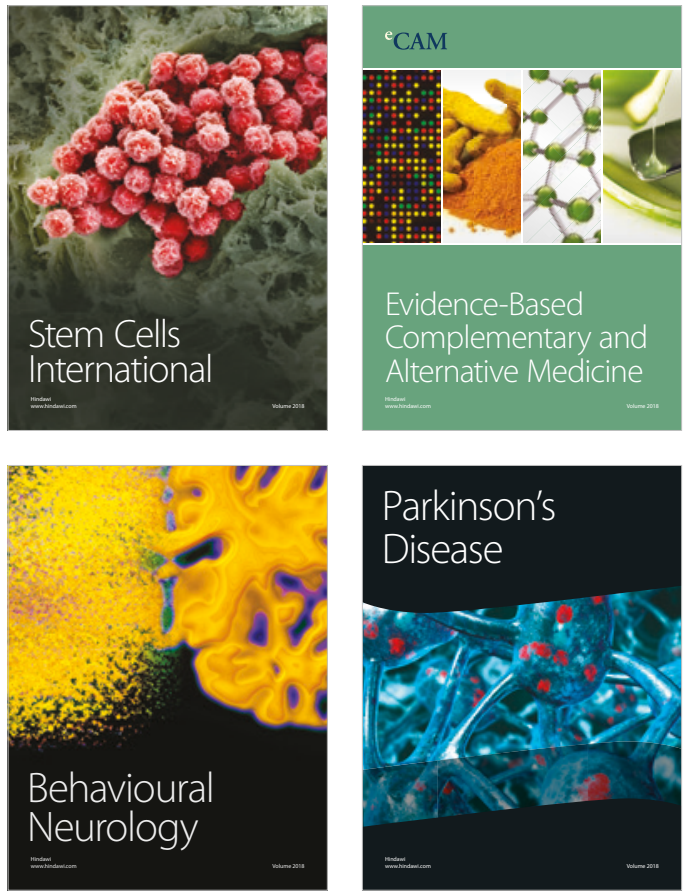

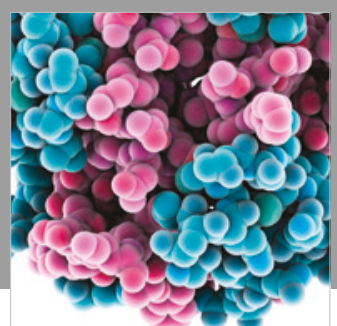

ournal of

Diabetes Research

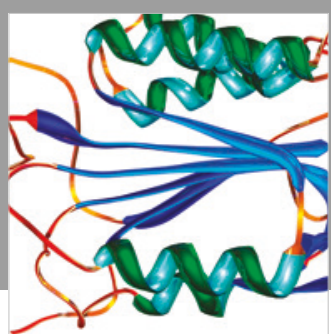

Disease Markers
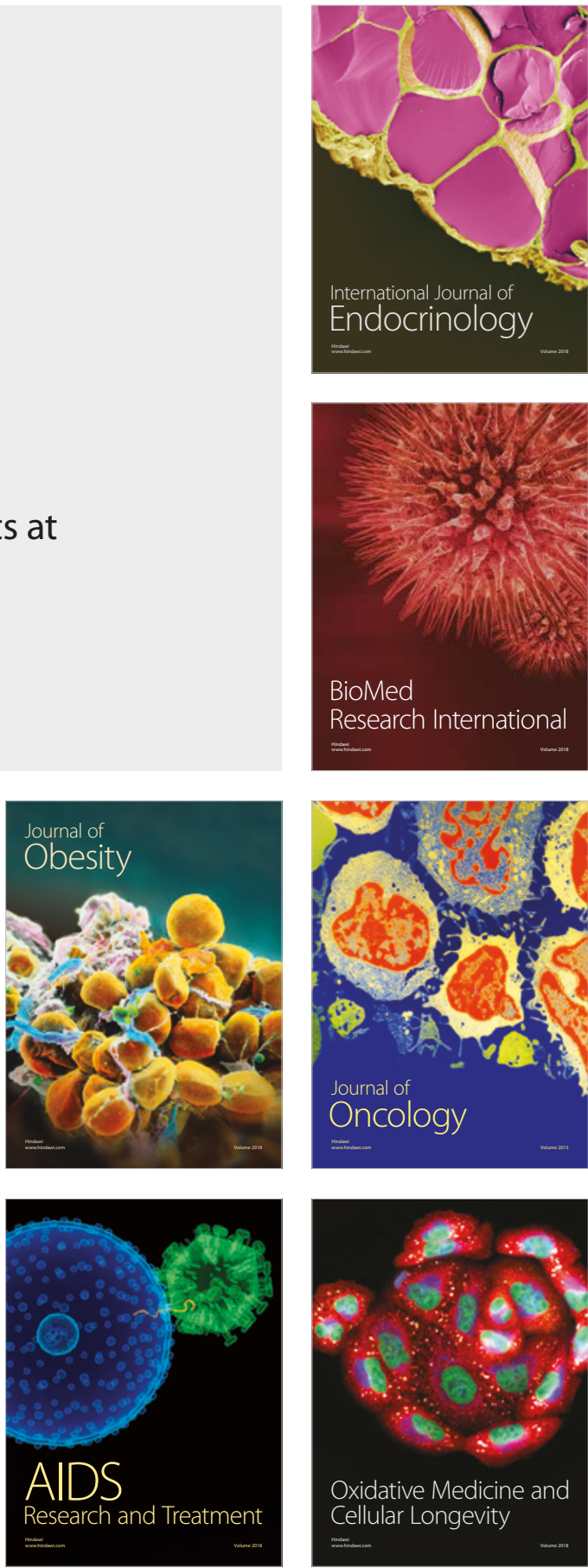